\title{
Arterial and End-Tidal Carbon Dioxide in Supine Obese Patients during General Anesthesia
}

\author{
Kenichi Satoh ${ }^{1 *}$, Mami Chikuda', Ayako Ohashi', Miho Kumagai' ${ }^{2}$, \\ Masahito Sato', Akiyoshi Kuji'2, Shigeharu Joh'1 \\ ${ }^{1}$ Division of Dental Anesthesiology, Department of Reconstructive Oral and Maxillofacial Surgery, School of \\ Dentistry, Iwate Medical University, Morioka, Japan \\ ${ }^{2}$ Division of Special Care Dentistry, Department of Developmental Oral Health Science, School of Dentistry, \\ Iwate Medical University, Morioka, Japan \\ Email: satoken@iwate-med.ac.jp
}

Received 1 April 2015; accepted 8 May 2015; published 13 May 2015

Copyright (C) 2015 by authors and Scientific Research Publishing Inc.

This work is licensed under the Creative Commons Attribution International License (CC BY).

http://creativecommons.org/licenses/by/4.0/

(c) (i) Open Access

\begin{abstract}
Background: We investigated the differences between partial pressure of arterial carbon dioxide and end-tidal carbon dioxide (P(a-ET) $\mathrm{CO}_{2}$ ) with respect to the Broca-Katsura index (BKI), which is an obesity index, in obese patients during general anesthesia. Materials and Methods: From January 2003 to December 2013, we studied 601 patients aged 16 years old or over undergoing general anesthesia. Patients had American Society of Anesthesiology physical status I and II and we reviewed their anesthetic charts. The $\mathrm{P}(\mathrm{a}-\mathrm{ET}) \mathrm{CO}_{2}$ with respect to the BKI divided patients into two groups: 16 to $<65$ years old, and $\geq 65$ years old, and compared the $\mathrm{P}(\mathrm{a}-\mathrm{ET}) \mathrm{CO}_{2}$ values between the two groups. Results: In patients aged 16 to $<65$ years old, the mean P(a-ET) $\mathrm{CO}_{2}$ was $2.2 \pm 3.1 \mathrm{mmHg}$ at BKI < $20 \%$; $3.3 \pm 3.1 \mathrm{mmHg}$ at $20 \%<\mathrm{BKI}<40 \%$; and $5.5 \pm 5.0 \mathrm{mmHg}$ at $40 \%<\mathrm{BKI}<60 \%$. In patients aged $\geq 65$ years old , the mean $\mathrm{P}(\mathrm{a}-\mathrm{ET}) \mathrm{CO}_{2}$ was $3.2 \pm 4.1 \mathrm{mmHg}$ at $\mathrm{BKI}<20 \%$; $4.3 \pm 3.6 \mathrm{mmHg}$ at $20 \%$ to $<40 \%$; and $4.4 \pm 3.3 \mathrm{mmHg}$ at $40 \%$ to $<60 \%$. Conclusion: The $\mathrm{P}(\mathrm{a}-\mathrm{ET}) \mathrm{CO}_{2}$ tends to increase in obese patients during general anesthesia with increasing BKI in patients aged 16 to $<65$ years old.
\end{abstract}

\section{Keywords}

Arterial-Alveolar Carbon Dioxide Tension Difference, Broca-Katsura Index, End-Tidal Carbon Dioxide, Partial Pressure of Arterial Carbon Dioxide, Supine Position

\footnotetext{
"Corresponding author.
}

How to cite this paper: Satoh, K., Chikuda, M., Ohashi, A., Kumagai, M., Sato, M., Kuji, A. and Joh, S. (2015) Arterial and End-Tidal Carbon Dioxide in Supine Obese Patients during General Anesthesia. Open Journal of Anesthesiology, 5, 79-84. http://dx.doi.org/10.4236/ojanes.2015.55016 


\section{Introduction}

End-tidal carbon dioxide $\left(\mathrm{ETCO}_{2}\right)$ measurement is an important measuring to identify intraoperative ventilatory problems in patients undergoing general anesthesia with tracheal intubation and positive pressure ventilation [1]. $\mathrm{ETCO}_{2}$ refers to the partial pressure of carbon dioxide at the end of expiration and reflects arterial carbon dioxide tension $\left(\mathrm{PaCO}_{2}\right)$ [2]. $\mathrm{ETCO}_{2}$ is used to set minute ventilation during general anesthesia but $\mathrm{ETCO}_{2}$ and $\mathrm{PaCO}_{2}$ are not identical during general anesthesia and the difference reflects the degree of alveolar dead space $\left(\mathrm{V}_{\text {Dalv }}\right)$ [3]. With ventilation-perfusion (V/Q) mismatch, $\mathrm{V}_{\text {Dalv }}$ increases and vascular resistance in high perfusion alveolar areas decreases, resulting in redistribution of blood flow away from low perfusion alveolar areas [3] [4], decreased $\mathrm{ETCO}_{2}$ results from the dilution effect of alveolar $\mathrm{PCO}_{2}\left(\mathrm{PaCO}_{2}\right)$ with gas from $\mathrm{V}_{\text {Dalv }}$ [3].

Obese patients undergoing general anesthesia in the supine position experience intrapulmonary shunting and V/Q mismatch [5] [6], which worsens with increasing body mass. Several previous reports discuss the differences between $\mathrm{ETCO}_{2}$ and $\mathrm{PaCO}_{2}\left(\mathrm{P}(\mathrm{a}-\mathrm{ET}) \mathrm{CO}_{2}\right)$, but none describe obese patients undergoing oral and maxillofacial surgery under general anesthesia. The Broca-Katsura index (BKI) [7]-[9] is an obesity index modified for Japanese patients and is used occasionally in preoperative anesthesia evaluation to determine whether an adult is obese. Few reports have evaluated $\mathrm{P}(\mathrm{a}-\mathrm{ET}) \mathrm{CO}_{2}$ with respect to the $\mathrm{BKI}$ during general anesthesia.

We investigated $\mathrm{P}(\mathrm{a}-\mathrm{ET}) \mathrm{CO}_{2}$ with respect to the $\mathrm{BKI}$ in obese patients undergoing oral and maxillofacial surgery during general anesthesia in the supine position, and divided patients into two groups: 16 to $<65$ years old and $\geq 65$ years old, and then compared the $\mathrm{P}(\mathrm{a}-\mathrm{ET}) \mathrm{CO}_{2}$ values between the two groups.

\section{Materials and Methods}

This retrospective study was approved by the Committee on Clinical Investigation for human research at Iwate Medical University (approval number, 01219). We analyzed the records of 519 patients aged $\geq 16$ years old undergoing general anesthesia for oral and maxillofacial surgery and dental procedures in our department from January 2003 to December 2013. Exclusions included smoking, respiratory disease, and cardiopulmonary disease. Additional inclusion criteria were an American Society of Anesthesiology (ASA) physical status of I and II and we retrospectively reviewed patients' charts for age, height, weight, \% forced vital capacity (\%FVC), \% forced expiratory volume in $1 \mathrm{~s}\left(\mathrm{FEV}_{1.0} \%\right)$, and the difference between $\mathrm{PaCO}_{2}$ and $\mathrm{ETCO}_{2}$.

Patients were first divided into two groups by age: 16 - 65 years old, and $\geq 65$ years old. Each group was then divided by BKI, which was calculated as follows: BKI(\%) $=$ \{weight in $\mathrm{kg}-($ height in centimeters -100$) \times$ $0.9\} /$ (height in centimeters -100$) \times 0.9$ to determine whether the adult was obese.

The first group (16 to $<65$ years old) was sub-divided into three groups: A group (normal; BKI $<20 \%$ ); B group (mild obesity; 20\% < BKI $<40 \%$ ); and C group (moderate obesity; $40 \%<$ BKI $<60 \%$ ). The second group ( $\geq 65$ years old) was also divided into three groups: D group (normal; BKI $<20 \%$ ); E group (mild obesity; $20 \%<$ BKI < 40\%); and F group (moderate obesity; $40 \%<$ BKI < 60\%).

Anesthesia was induced with intravenous propofol (1 - $2 \mathrm{mg} / \mathrm{kg}$ of ideal body weight) or thiopental sodium (3 - $5 \mathrm{mg} / \mathrm{kg}$ of ideal body weight), and vecuronium bromide $(0.1 \mathrm{mg} / \mathrm{kg}$ of ideal body weight) or rocuronium bromide $(0.8 \mathrm{mg} / \mathrm{kg}$ of ideal body weight) was used to induce muscle relaxation. After tracheal intubation, anesthesia was maintained in almost all patients with sevoflurane $(1 \%-2 \%)$ and nitrous oxide gas if necessary, and mechanical ventilation. We used an oral $\mathrm{RAE}^{\circledR}$ (Covidien, Mallinckrodt, Ireland) cuffed endotracheal tube with a Murphy's eye for oral intubation and the Parker Flex-Tip ${ }^{\circledR}$ PFHV (Parker Medical, Highlands Ranch, CO, USA) with nasal intubation. The ventilator settings were as follows: tidal volume $8-10 \mathrm{ml} / \mathrm{kg}$ of ideal body weight, respiratory rate 10 - 12 breaths/min, peak airway pressure $<20 \mathrm{~cm} \mathrm{H}_{2} \mathrm{O}$, PEEP $0 \mathrm{~cm} \mathrm{H}_{2} \mathrm{O}$, and inspiratory oxygen concentration $33 \%$ or $40 \%$. A blood sample was drawn from the radial artery or dorsalispedis artery and analyzed for blood gases 30 - 60 min from the start of the procedure once the patient was stable.

Values are presented as mean \pm S.D. SPSS version 11.0 (SPSS, Inc., Chicago, IL, USA) was used for statistical analysis, using one-way ANOVA followed by multiple-comparison testing using the Scheffe test among groups. The relationship between $\mathrm{P}(\mathrm{a}-\mathrm{ET}) \mathrm{CO}_{2}$ and BKI or age was investigated by Pearson's correlation coefficient test. Correlation coefficients were obtained using simple regression analysis (Excel software, 2003; Microsoft, Redmond, WA, USA). Significance was set at a p-value $<0.05$.

\section{Results}

Patient characteristics and laboratory data are presented in Table 1. Comparing groups A, B, and C, we found 
Table 1. Patients’ profiles and laboratory data by BKI and age. (a) aged 16 - 65 years old; (b) aged $\geq 66$ years old.

(a)

\begin{tabular}{cccc}
\hline Broca-Katsura index (\%) & 0 to $<20$ & 20 to $<40$ & 40 to $<60$ \\
Group & A & B & C \\
Number & 208 & 127 & $48.4 \pm 14.4$ \\
Age (yrs) & $43.1 \pm 14.8$ & $46.0 \pm 13.5$ & $159.6 \pm 9.7$ \\
Height (cm) & $163.7 \pm 8.8$ & $160.2 \pm 9.0$ & $78.4 \pm 11.7^{*, \dagger}$ \\
Weight (kg) & $58.5 \pm 9.9$ & $109.0 \pm 4.1$ & $108.3 \pm 1.4$ \\
\%FVC (\%) & $112.5 \pm 15.6$ & $82.2 \pm 6.1$ & $83.1 \pm 2.2$ \\
FEV & $82.4 \pm 5.9$ & $3.3 \pm 3.1 *$ & $5.5 \pm 5.0^{*, \dagger}$ \\
\hline
\end{tabular}

${ }^{*} \mathrm{p}<0.05$ vs. group $\mathrm{A},{ }^{\dagger} \mathrm{p}<0.05$ vs. group $\mathrm{B}$.

(b)

\begin{tabular}{cccc}
\hline Broca-Katsura index (\%) & 0 to $<20$ & 20 to $<40$ & 40 to $<60$ \\
\hline Group & $\mathrm{D}$ & $\mathrm{E}$ & $\mathrm{F}$ \\
Number & 85 & 40 & $74.9 \pm 6.4$ \\
Age (yrs) & $74.3 \pm 5.2$ & $73.6 \pm 6.1$ & $149.1 \pm 9.1^{*}$ \\
Height (cm) & $154.7 \pm 8.3$ & $150.8 \pm 8.2$ & $66.2 \pm 12.2^{*, \dagger}$ \\
Weight (kg) & $51.3 \pm 7.7$ & $60.1 \pm 8.9^{*}$ & $99.2 \pm 13.2$ \\
\%FVC (\%) & $102.8 \pm 19.0$ & $102.0 \pm 13.7$ & $81.1 \pm 10.6$ \\
FEV $_{1.0} \%(\%)$ & $78.6 \pm 5.1$ & $81.3 \pm 8.5^{*}$ & $4.8 \pm 3.3$ \\
\hline
\end{tabular}

${ }^{*} \mathrm{p}<0.05$ vs. group $\mathrm{E},{ }^{\dagger} \mathrm{p}<0.05$ vs. group $\mathrm{F}$. Data are presented as mean \pm standard deviation.

no significant differences in age, height, \%FVC, or $\mathrm{FEV}_{1.0} \%$, and significant differences in body weight and $\mathrm{P}(\mathrm{a}-\mathrm{ET}) \mathrm{CO}_{2}$. The mean $\mathrm{P}(\mathrm{a}-\mathrm{ET}) \mathrm{CO}_{2}$ was $2.2 \pm 3.1 \mathrm{mmHg}$ at $\mathrm{BKI}<20 \%$; $3.3 \pm 3.1 \mathrm{mmHg}$ at $20 \%<\mathrm{BKI}<40 \%$; and $5.5 \pm 5.0 \mathrm{mmHg}$ at $40 \%<\mathrm{BKI}<60 \%$. The $\mathrm{P}(\mathrm{a}-\mathrm{ET}) \mathrm{CO}_{2}$ increased significantly with BKI (Table 1).

Comparing groups $\mathrm{D}, \mathrm{E}$, and $\mathrm{F}$, we found no significant differences in age, $\% \mathrm{FVC}, \mathrm{FEV}_{1.0} \%$, or $\mathrm{P}(\mathrm{a}-\mathrm{ET}) \mathrm{CO}_{2}$, with significant differences in height comparing group $\mathrm{F}$ with group $\mathrm{D}$ and $\mathrm{FEV}_{1.0} \%$ comparing group $\mathrm{E}$ with group D. The mean a-ETCO ${ }_{2}$ was $4.3 \pm 3.5 \mathrm{mmHg}$ at $\mathrm{BKI}<20 \%, 4.7 \pm 3.0 \mathrm{mmHg}$ at $20 \%<\mathrm{BKI}<40 \%$; and $4.8 \pm 3.3 \mathrm{mmHg}$ at $40 \%<\mathrm{BKI}<60 \%$. The $\mathrm{P}(\mathrm{a}-\mathrm{ET}) \mathrm{CO}_{2}$ tended to increase with increasing BKI (Table 1).

In group at age of 16 to $<65$ (Figure 1), the correlation between $\mathrm{P}(\mathrm{a}-\mathrm{ET}) \mathrm{CO}_{2}$ and $\mathrm{BKI}(20 \%$ to $<60 \%)$; $\mathrm{P}(\mathrm{a}-\mathrm{ET}) \mathrm{CO}_{2}$ linearly increased with increasing $\mathrm{BKI}\left(\mathrm{P}(\mathrm{a}-\mathrm{ET}) \mathrm{CO}_{2}=1.5744+0.0839 \times \mathrm{BKI} ; R=0.22 ; \mathrm{p}<0.05\right)$, and there was a slight correlation between the two. In group $20 \%<\mathrm{BKI}<40 \%$ and $40 \%<\mathrm{BKI}<60 \%$, there was not a significant correlation between $\mathrm{P}(\mathrm{a}-\mathrm{ET}) \mathrm{CO}_{2}$ and age $(R=0.068$ and 0.058$)$. In group at age of $\geq 65$ (Figure 2), there was not a significant correlation between $\mathrm{P}(\mathrm{a}-\mathrm{ET}) \mathrm{CO}_{2}$ and $\mathrm{BKI}(20 \%$ to $<60 \%)(R=0.033)$. In group $20 \%<\mathrm{BKI}<40 \%$, there was a slight correlation between the two $(R=0.322$; $\mathrm{p}<0.05)$. In group $40 \%<$ $\mathrm{BKI}<60 \%$, there was not a significant correlation between $\mathrm{P}(\mathrm{a}-\mathrm{ET}) \mathrm{CO}_{2}$ and $\mathrm{BKI}(20 \%$ to $<60 \%)(R=0.076)$.

\section{Discussion}

In this study we found out two important issues. A standard value for $\mathrm{P}(\mathrm{a}-\mathrm{ET}) \mathrm{CO}_{2}$ in obese patients in the supine position during general anesthesia is determined with respect to BKI. The $\mathrm{P}(\mathrm{a}-\mathrm{ET}) \mathrm{CO}_{2}$ tends to increase in patients aged 16 to $<65$ years old, and in those aged $\geq 65$ years old.

First, a standard value for $\mathrm{P}(\mathrm{a}-\mathrm{ET}) \mathrm{CO}_{2}$ in obese patients in the supine position during general anesthesia is 


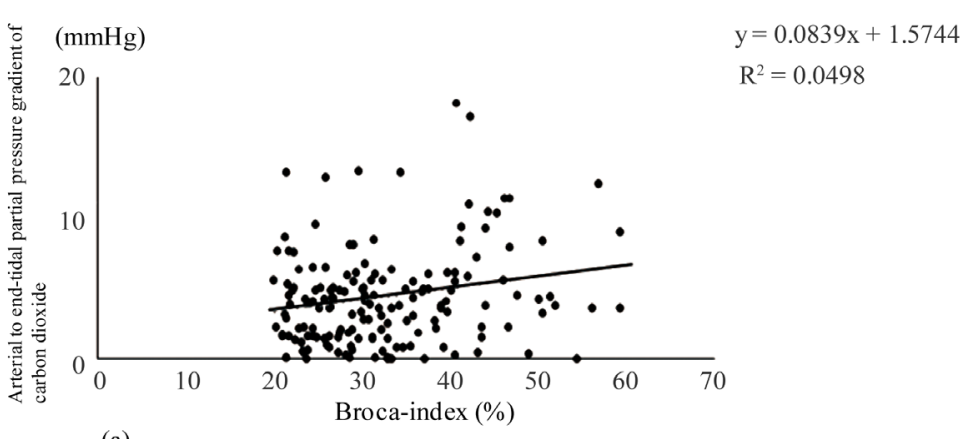

(a)

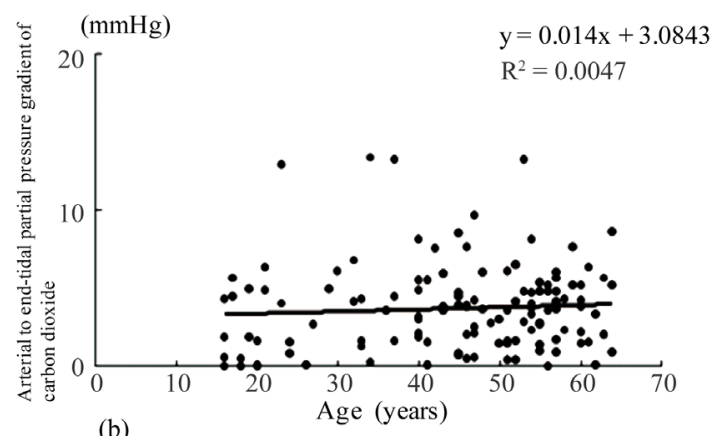

(b)

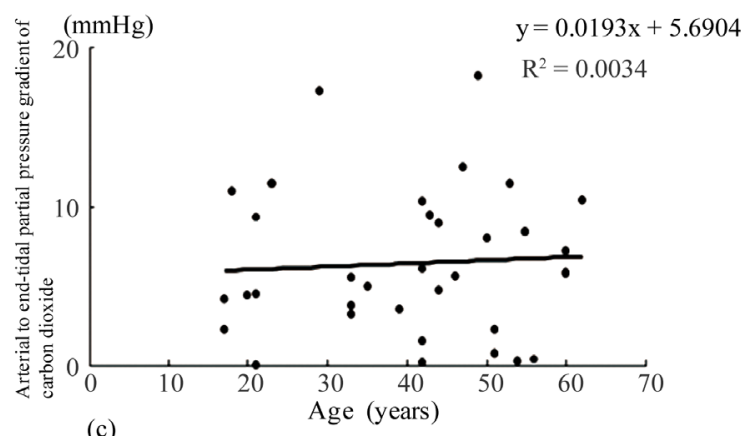

(c)

Figure 1. Relationship between arterial to end-tidal partial pressure gradient of carbon dioxide and Broca-index at $20 \%$ to $<60 \%$ or age between 16 to $<65$ years old. (a) Broca-Katsura index at $20 \%$ to $<60 \%$; (b) Broca-Katsura index at $20 \%$ to $<40 \%$; (c) Broca-Katsura index at $40 \%$ to $<60 \%$.
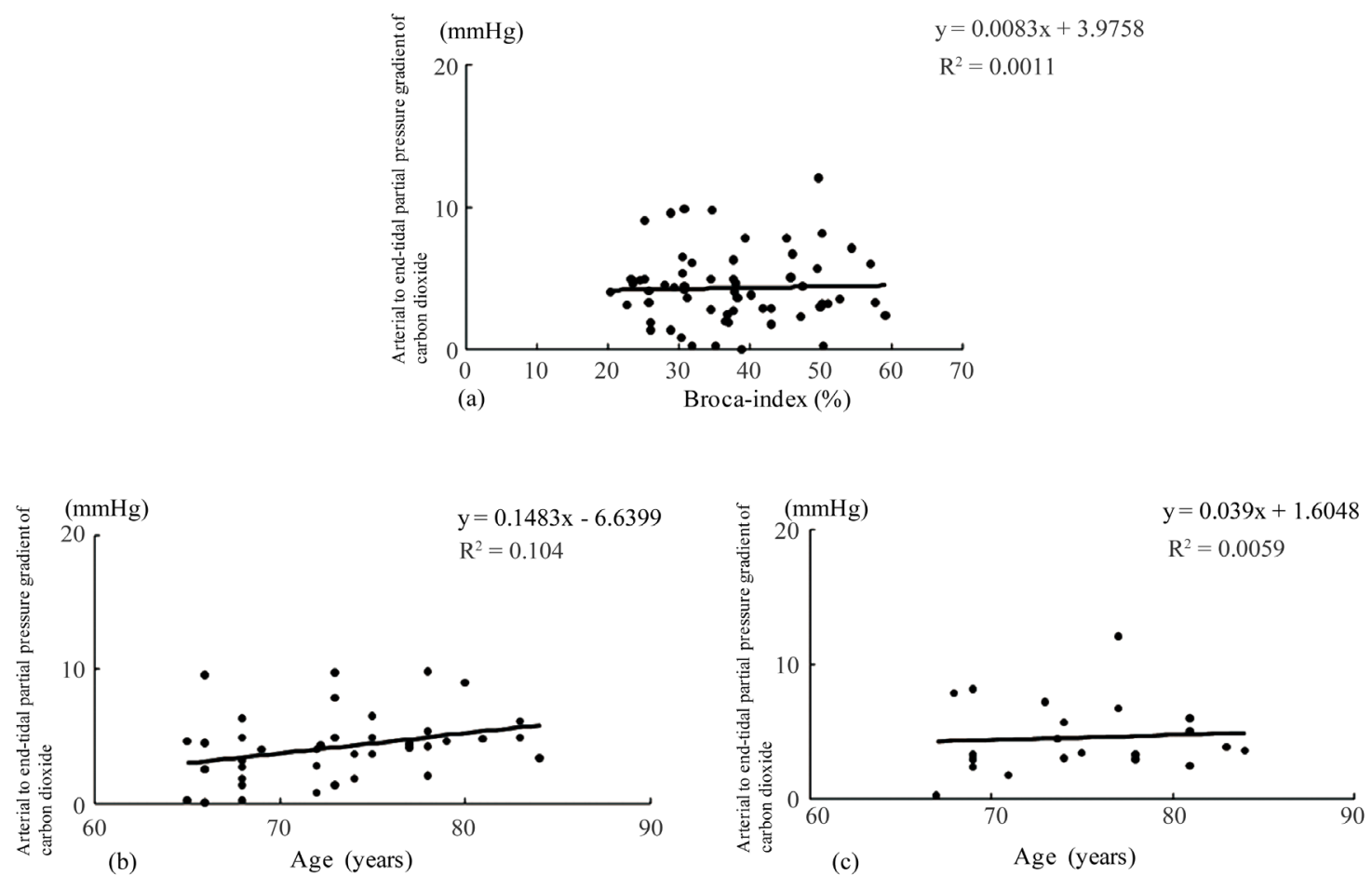

Figure 2. Relationship between arterial to end-tidal partial pressure gradient of carbon dioxide and Broca-index at 20 to $<60 \%$ or age $\geq 65$ years old. (a) Broca-Katsura index at $20 \%$ to $<60 \%$; (b) Broca-Katsura index at $20 \%$ to $<40 \%$; (c) Broca-Katsura index at $40 \%$ to $<60 \%$. 
determined with respect to $\mathrm{BKI}$. The mean $\mathrm{P}(\mathrm{a}-\mathrm{ET}) \mathrm{CO}_{2}$ was $2.2 \pm 3.1 \mathrm{mmHg}$ at $\mathrm{BKI}<20 \%$; $3.3 \pm 3.1 \mathrm{mmHg}$ at $20 \%<\mathrm{BKI}<40 \%$; and $5.5 \pm 5.0 \mathrm{mmHg}$ at $40 \%<\mathrm{BKI}<60 \%$ in group at the age of 16 to $<65$. The mean a-ETCO ${ }_{2}$ was $4.3 \pm 3.5 \mathrm{mmHg}$ at $\mathrm{BKI}<20 \%, 4.7 \pm 3.0 \mathrm{mmHg}$ at $20 \%<\mathrm{BKI}<40 \%$ and $4.8 \pm 3.3 \mathrm{mmHg}$ at $40 \%$ $<\mathrm{BKI}<60 \%$ in group at the age of $\geq 65$. Generally, $\mathrm{ETCO}_{2}$ is a function of alveolar ventilation, pulmonary perfusion, $\mathrm{CO}_{2}$ production, and the ventilation-perfusion relationship [10]. In patients without lung disease, who are undergoing general anesthesia, $\mathrm{ETCO}_{2}$ is presumed to be approximately $5 \mathrm{mmHg}$ lower than the $\mathrm{PaCO}_{2}$ value under normal steady state conditions [11]. The changes in $\mathrm{P}(\mathrm{a}-\mathrm{ET}) \mathrm{CO}_{2}$ are due to changes in $\mathrm{ETCO}_{2}$ because $\mathrm{PaCO}_{2}$ remains constant. The exception to this is when $\mathrm{F}_{\mathrm{I}} \mathrm{O}_{2}=0.97$ and changes are more likely to be due to the dilution effect of alveolar $\mathrm{PaCO}_{2}$ with gas from alveolar dead space $\left(\mathrm{V}_{\text {Dalv }}\right)$ [3]. The mechanism explaining increasing $\mathrm{V}_{\text {Dalv }}$ with increasing $\mathrm{F}_{\mathrm{I}} \mathrm{O}_{2}$ was that high $\mathrm{F}_{\mathrm{I}} \mathrm{O}_{2}$ reduced vascular resistance in high perfusion alveolar areas, resulting in the redistribution of blood flow away from alveolar perfusion [3] [4]. The $\mathrm{P}(\mathrm{a}-\mathrm{ET}) \mathrm{CO}_{2}$ was primarily a reflection of respiratory dead space (primarily alveolar dead space), and to a lesser degree, may also reflect venous admixture [12]. The $\mathrm{P}(\mathrm{a}-\mathrm{ET}) \mathrm{CO}_{2}$ found in neurosurgical patients during craniotomy suggested the presence of higher intraoperative respiratory dead space than previously reported for surgery patients [13]. Intrapulmonary shunting is also thought to influence $\mathrm{P}(\mathrm{a}-\mathrm{ET}) \mathrm{CO}_{2}$, leading to increased differences resulting from increased $\mathrm{PaCO}_{2}$ with venous admixture [3]. A major cause of intrapulmonary shunting during general anesthesia is the development of atelectasis [14]. However, induction-induced atelectasis likely persists, having little impact on the phase increases in $\mathrm{P}(\mathrm{a}-\mathrm{ET}) \mathrm{CO}_{2}[3]$.

Second, the $\mathrm{P}(\mathrm{a}-\mathrm{ET}) \mathrm{CO}_{2}$ tends to increase in patients aged 16 to $<65$ years old, and in those aged $\geq 65$ years old. In group at the age of 16 to $<65$, there was a slight correlation between $\mathrm{P}(\mathrm{a}-\mathrm{ET}) \mathrm{CO}_{2}$ and $\mathrm{BKI}(20$ to $<60 \%)$ $(R=0.22 ; \mathrm{p}<0.05)$. In group at the age of $\geq 65$, there was a slight correlation between $\mathrm{P}(\mathrm{a}-\mathrm{ET}) \mathrm{CO}_{2}$ and age $(R=$ 0.322; p < 0.05) in group 20\% < BKI < 40\%. Pelosi et al. [15] reported that $\mathrm{PCO}_{2}$ was not correlated with Body Mass Index during general anesthesia, as previously reported in awake and anesthetized obese subjects without obesity hypoventilation syndrome [16]. It was thought that in obese patients the increased $\mathrm{P}(\mathrm{a}-\mathrm{ET}) \mathrm{CO}_{2}$ was caused by decreases in $\mathrm{ETCO}_{2}$ resulting from the dilution effect of $\mathrm{PaCO}_{2}$ with gas from $\mathrm{V}_{\text {Dalv }}$ [3]. This is based on intrapulmonary shunting and V/Q mismatch developing with increasing body mass or BKI [5] [6]. Although the mechanisms explaining the development of intrapulmonary shunting and V/Q mismatch during general anesthesia in our study are unclear, we believe that the major causes of $\mathrm{P}(\mathrm{a}-\mathrm{ET}) \mathrm{CO}_{2}$ with increasing $\mathrm{BKI}$ are likely related to decreased $\mathrm{ETCO}_{2}$ resulting from the $\mathrm{PaCO}_{2}$ dilution with gas from $\mathrm{V}_{\text {Dalv }}$. In this study, the correlation between $\mathrm{P}(\mathrm{a}-\mathrm{ET}) \mathrm{CO}_{2}$ and age was lower $(R=0.322)$ than that reported previously in other clinical situations. In a study of elective craniotomies, Russell and Graybeal [13] reported a correlation coefficient (r) of 0.632 in the supine position and an $\mathrm{r}^{2}$ of 0.61 in the supine position. The $\mathrm{ETCO}_{2}$ did not provide a stable reflection of $\mathrm{PaCO}_{2}$ in this study.

There are some limitations to our study. First, the data in this study are measured at one time during general anesthesia. It is needed to be compared at least two points. But we believe that the data provided accurate and reliable information on the changes in $\mathrm{P}(\mathrm{a}-\mathrm{ET}) \mathrm{CO}_{2}$ in obese patients and are clinically useful for management of anesthesia. Second, these data are only determined on Japanese obese patients since the Broca-Katsura index is an obesity index modified for Japanese patients. Further research needs to be done to investigate whether our results correlate with Body Mass Index.

\section{Conclusion}

We evaluated $\mathrm{P}(\mathrm{a}-\mathrm{ET}) \mathrm{CO}_{2}$ with respect to $\mathrm{BKI}$, an obesity indicator, in obese patients in supine position during general anesthesia. A standard value for $\mathrm{P}(\mathrm{a}-\mathrm{ET}) \mathrm{CO}_{2}$ in obese patients in the supine position during general anesthesia is determined with respect to BKI. The $\mathrm{P}(\mathrm{a}-\mathrm{ET}) \mathrm{CO}_{2}$ tends to increase in patients aged 16 to $<65$ years old, and in those aged $\geq 65$ years old. We believe that the data provide reliable information on the changes in $\mathrm{P}(\mathrm{a}-\mathrm{ET}) \mathrm{CO}_{2}$ and are clinically useful for management of anesthesia in obese patients.

\section{Acknowledgments}

None.

\section{Conflicts of Interests}

Kenichi Satoh, Mami Chikuda, Ayako Ohashi, Miho Kumagai, Masahito Satoh, Akiyoshi Kuji and Shigeharu 
Joh have no conflicts of interests or financial ties to disclose.

\section{References}

[1] Campbell, F.A., McLeod, M.E., Bissonnette, B. and Swartz, J.S. (1994) End-Tidal Carbon Dioxide Measurement in Infants and Children during and after General Anaesthesia. Canadian Journal of Anesthesia, 41, 107-110. http://dx.doi.org/10.1007/BF03009801

[2] Bhavani-Shankar, K., Moseley, H., Kumar, A.Y. and Delph, Y. (1992) Capnometry and Anaesthesia. Canadidan Journal of Anesthesia, 39, 617-632. http://dx.doi.org/10.1007/BF03008330

[3] Yamauchi, H., Ito, S., Sasano, H., Azami, T., Fisher, J. and Sobue, K. (2011) Dependence of the Gradient between Arterial and End-Tidal $\mathrm{PCO}_{2}$ on the Fraction of Inspired Oxygen. British Journal of Anaesthesia, 107, 631-635. http://dx.doi.org/10.1093/bja/aer171

[4] Larson Jr., C.P. and Severihnghous, J.W. (1962) Postural Variations in Dead Space and $\mathrm{CO}_{2}$ Gradients Breathing Air and $\mathrm{O}_{2}$. Journal of Applied Physiology, 17, 417-420.

[5] Tokics, L., Hendenstierna, G., Strandberg, A., Brismar, B. and Lundquist, H. (1987) Lung Collapse and Gas Exchange during General Anesthesia: Effects of Spontaneous Breathing, Muscle Paralysis, and Positive End-Expiratory Pressure. Aneshtesiology, 66, 157-167. http://dx.doi.org/10.1097/00000542-198702000-00009

[6] Rothen, H.U., Sporre, B., Engberg, G., Wegenius, G. and Hedenstierna, G. (1998) Airway Closure, Atelectasis and Gas Exchange during General Anaesthesia. British Journal of Anaeshtesia, 81, 681-686.

[7] Omura, M., Zinno, S., Harada, T. and Inoue, N. (1993) Evaluation of Validity of Five Weight-Height Obesity Indices. Fukuoka Igaku Zassi (Hukuoka Acta Medica), 84, 305-310.

[8] Nishida, M. and Funahashi, T. (2009) Validity of Indices (BMI, Rorre Index, Brocha Method) for Assessment of Obesity. Nihon Rinsho, 67, 301-306.

[9] Park, W. and Park, S. (2013) Body Shape Analyses of Large Persons in South Korea. Ergonomics, 56, $692-706$. http://dx.doi.org/10.1080/00140139.2012.752529

[10] Nunn, J.F. (1993) Carbon Dioxide. In: Nuun, J.F., Ed., Nuun's Applied Respiratory Physiology, Butterworth-Heinemann, Cambridge, 219-246. http://dx.doi.org/10.1016/B978-0-7506-1336-1.50016-4

[11] Suominen, P.K., Staiyer, S., Wang, W. and Chang, A.C. (2007) The Effect of Temperature Correction of Blood Gas Values on the Accuracy of End-Tidal Carbon Dioxide Monitoring in Children after Cardiac Surgery. ASAIO Journal, 53, 670-674. http://dx.doi.org/10.1097/MAT.0b013e3181569bf3

[12] Nunn, J.F. (1987) Carbon Dioxide. In: Nunn, J.F., Ed., Applied Respiratory Physiology, 3rd Edition, Butterworth, London, 207-234. http://dx.doi.org/10.1016/B978-0-407-00342-2.50015-7

[13] Russel, G.B. and Graybeal, J.M. (1995) The Arterial to End-Tidal Carbon Dioxide Difference in Neurosurgical Patients during Craniotomy. Anesthesia and Analgesia, 81, 806-810. http://dx.doi.org/10.1097/00000539-199510000-00025

[14] Bendixen, H.H., Whyte, J. and Laver, M.B. (1963) Impaired Oxygenation in Surgical Patients during General Anesthesia with Controlled Ventilation: A Concept of Atelectasis. The New England Journal of Medicine, 269, 991-996. http://dx.doi.org/10.1056/NEJM196311072691901

[15] Pelosi, P., Croci, M., Ravagnan, I., Tredici, S., Pedoto, A., Lissoni, A. and Gattinoni, L. (1998) The Effects of Body Mass on Lung Volumes, Respiratory Mechanics, and Gas Exchange during General Anesthesia. Anesthesia and Analgesia, 87, 654-660. http://dx.doi.org/10.1097/00000539-199809000-00031

[16] Hedensterna, G. and Santesson, J. (1976) Breathing Mechanics, Dead Space and Gas Exchange in the Extremely Obese, Breathing Spontaneously and during Anesthesia with Intermittent Positive Pressure Ventilation. Acta Anaesthesiologica Scandinavica, 20, 248-254. http://dx.doi.org/10.1111/j.1399-6576.1976.tb05036.x

\section{Abbreviations}

$\mathrm{ETCO}_{2}$ : end-tidal carbon dioxide;

$\mathrm{PaCO}_{2}$ : partial pressure of arterial carbon dioxide;

BKI: Broca-Katsura index;

$\mathrm{P}(\mathrm{a}-\mathrm{ET}) \mathrm{CO}_{2}$ : arterial to end-tidal partial pressure gradient of carbon dioxide;

$\mathrm{F}_{\mathrm{I}} \mathrm{O}_{2}$ : fraction of inspiratory oxygen. 